\title{
An Approach to Identify Product Purchase Processing Time by Applying Business Intelligence in Steel Coated Production
}

\author{
Anupam Anant Kher ${ }^{1}$ and Swati Hira² \\ ${ }^{1}$ Department of Mining Engineering, \\ ${ }^{2}$ Department of Computer \\ Science \& Engineering, ${ }^{1}$ Visvesvaraya National Institute of Technology, , \\ ${ }^{2}$ Shri Ramdeobaba College of Engineering and Management, Nagpur, India
}

\section{ABSTRACT}

Indirect materials procurement, mostly consist of low volume and high variety still technically they are not a part of the end sale product, even they are having same important as direct material. For example, in an automated production line power grind to a halt without a grinding wheel indirect material, hence procurement and presence of indirect materials at right time is of major importance.The reduction of non-value added activities in this process deduction of non-value added actionswould result in the reduction of lead time and buyers administrative efforts. Hence, this study has been interpretedto improving effectiveness and efficiency of the current procurement process. The objective of this study is to analyze and determine different aspects of the process of Purchase Requisition (PR) to Purchase Order (P0) and their analysis. We use power BI for interactive analysis and visualization. We applied our approach on steel coated products. Proposed approach benefits the procurement process and helps to retainconversion time and reduce the breakdown period.

\section{KEY WORDS: PURCHASE REQUISITION, PURCHASE ORDER, PURCHASE DEPARTMENT, BUSINESS INTELLIGENCE, DATA} ANALYSIS

\section{INTRODUCTION}

Purchasing department plays a major role in the procurement process [Xue et al., 2012] to procure all necessary materials needed for production or daily operation of the company or government organization. For a manufacturing company, this might include raw materials such as iron, steel, aluminum or plastics, but it also might include tools, machinery, delivery trucks

\section{ARTICLE INFORMATION}

*Corresponding Author: anupamkher@mng.vnit.ac.in Received 18th Oct 2020 Accepted after revision 23rd Dec 2020 Print ISSN: 0974-6455 Online ISSN: 2321-4007 CODEN: BBRCBA

Thomson Reuters ISI Web of Science Clarivate Analytics USA and Crossref Indexed Journal

\section{Clarivate
Analytics}

NAAS Journal Score 2020 (4.31)

A Society of Science and Nature Publication,

Bhopal India 2020. All rights reserved.

Online Contents Available at: http//www.bbrc.in/

Doi: http://dx.doi.org/10.21786/bbrc/13.14/7 or even the office supplies needed for the secretaries and sales team. In a retail environment, the purchasing department makes sure there is always sufficient product on the shelves or in the warehouses to keep the customers happy and keep the store well-stocked. With a small business, it is especially important to keep inventory ordering at a reasonable level; investing large amounts of capital in excess stock could result in storage problems and in a shortage of capital for other expenditures such as advertising or research and development. A purchasing department also is charged with continuously evaluating whether it is receiving these materials at the best possible price in order to maximize profitability. Figure 1, describes different tasks performed by purchase department.

In our study, we apply our approach on the company [JSW Group] which is India's leading private sector steel producer and among the world's most illustrious steel

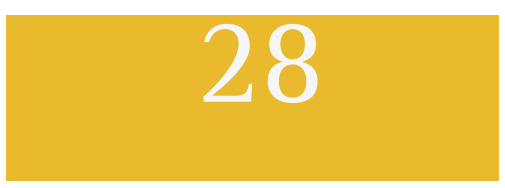


companies. The Steel Coated Products manufacturing organization under study is been divided into 3 main categories as shown in the Figure 2.The above flow chart shows us the three main processes in plant. When we discuss about data analyticsfor procurement and sourcing, basically we're discussing about to making data sensual that is interned by supplier information, systems through the source-to-settle process, relevant supplier third-party data, suppliers, complex categories and markets. Assessing procurement data in this form is of more importance than simple analytics and reporting. Now a days enterprise system generate and capture massive volumes of data with the everyday increase in automation level.

Figure 1: Functionality of purchase department

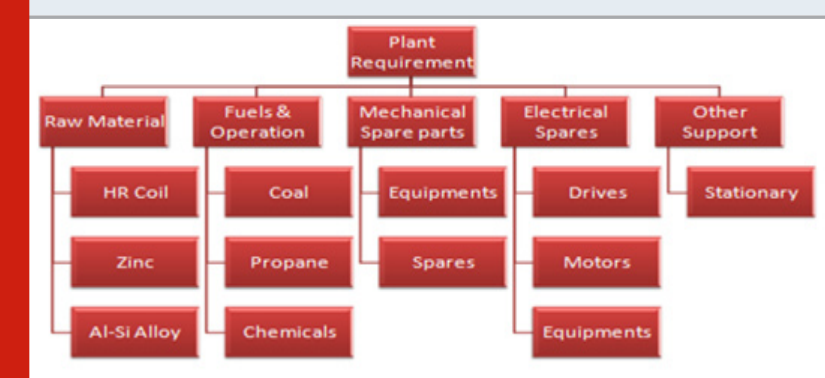

Figure 2: Categorization of steel coated products

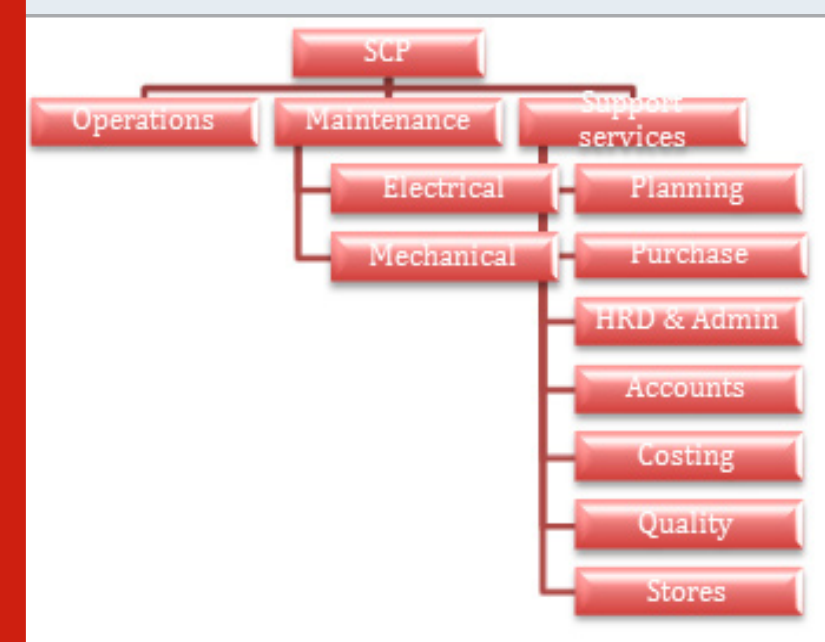

Large-scale automation of procurement processes is increasingly producing high volumes of data that can bring new insight into the business, helping it to better understand how the supply chain needs to evolve and adapt [Ballou 2007 and Bowersox 2010].The potential of analytics in procurement is so great that the higherlevel value proposition sought by so many working in contemporary procurement becomes a real possibility, be it tackling complex spend categories, proactively mitigating supplier risks or effectively monitoring the performance of suppliers. Overall, analytics can help procurement offer more to the business strategically. So our motivation is to provide an analysis for PR to PO time by providing an interactive visualization. The use of analytics in procurement offers an opportunity for organizations to consolidate, cleanse and connect spend and supplier data across the enterprise. Analytics can provide CPOs with greater visibility and unlock insights, helping them to reduce costs, drive compliance, mitigate risks, improve business intelligence and manage and develop suppliers. When the power of Big Data for Procurement is analyzedproperly, thisgives actionable business intelligence solution by identifying numerous trends and correlations which cannot be identified with traditional data analysis techniques and tools. This paper provides an insight on PR to PO cycle of procurement process.

\section{Purchase Process: Steps involve from PR to PO}

- The process starts with generation of requirement in SAP. That means a purchase request has been made by the company people. Then the purchase request gets approved by the head of the department by which purchase request has been generated.

- After the approval the request comes to purchase department. Purchase people now check the purchase request weather material specification is correct or not or quantity, price, or is the material has any past data of it or not.

- After the verification enquiry is sent to different parties for quotation by email. The management believes that there must be a minimum of three quotations for any material.

- After receiving the quotations by e-mail the hard copy of it is sent for technical recommendation to the end user. The user will provide TR ranking to the quotations. TR ranking means the quotation has been rejected completely.

- After the TR ranking initial comparison of the quotations are done, followed by negotiation. Negotiation can be done manually or by reverse auction. After that final comparison of the quotations is done and again the ranks are provided.

- The lowest party wins and note for approval is generated. Once the note is approved PO is created in SAP.

\section{METHODOLOGY}

- Before performing the actual analysis on the gathered information, we perform several tasks, listed below as follows:

- Data collection: This collection process involves Plant visit, Discussion with the plant employee and product portfolio to understand purchase process. Thesteel plant has a pickling line, two rolling mills, two galvanizing lines, two colour-coating lines, a Galvalume line, six slitting and 7 cut-to-length lines, two profiling lines and a tile profiling line.

Data preprocessing: Data preprocessing [Famili 1997 and MitraDebnath 2014] involves transforming the raw data into an understandable and efficient format. Real-world data problems can occur in many flavors which involves incompleteness, inconsistency, irrelevant or lacking in certain behaviors or trends, manual data input, wrong 
data types, regional formats and is likely to contain many errors. To resolving such issues we first preprocess the company data according to our requirement and make it relevant by handling noise and missing data.Figure 3 describes the necessary steps required to place an order after finalization of the raw material.

Figure 3: Purchase process (PR to PO)

\section{Purchase Process}

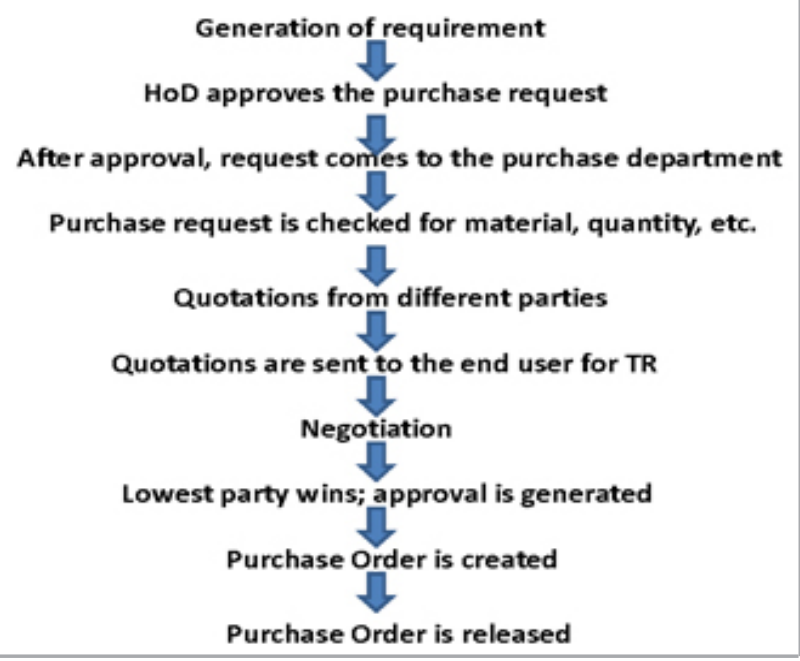

Data analysis: Analysis refers to breaking a whole into its separate components for individual examination. Data analysis [Keim 2006 and Hira 2015] is a process for obtaining the data and converting it into information useful for decision-making and suggesting conclusions. Data is collected and analyzed to answer questions, test hypotheses or disprove theories. We have used Microsoft Power BI [Lachev 2018 and Raj 2016] business analytics service. It provides attractive and interpretive visualizations with self-service BI capabilities, where dashboards and reports can be created by end users, without having dependency on technical staff (IT) or database administrators.

Experimentation evaluation: In this section, we perform analysis on steel plant dataset using power BI. The analysis were conducted on a Windows 7 machine with 2.30 GHz CPU and 4.00 GB RAM. Here, we first describe the dataset, and then the extracted results of our approach. Power BI makes this categorization and plotting graphs much simpler when compared to excel or some other tool. The Dashboard gives a preview of all comparisons that have been made. In Figure 4, the product are described based on categories, total vendors and total items their cost share for time period 20152017. We can see from figure that in dataset we have 18 material categories (such as ADM, SPM, SPE, and RMS etc), 550 vendors and 4776 items. We analyzed all the parameters related with PR to PO process. Various analysis are performed and outcomes are described as follows:
We first categorized the materials into its type and then made it available for sorting and studying. About 20 categories were studied whose PR to PO conversion time was calculated and then the average time was also determined of the same. Average time for these categories ranged from 4 days to nearly 108 days. Categories having average time greater than 80 days were further filtered and products contributing with maximum no of days were determined.In figure 5, maximum and average conversion time and delivery for a material is shown. It means total time required for a material form product requisition to its ordering is displayed. We then tried analyzing the data based on the quantity in which the products were categorized into bulk or regular. Any order above 1000 number was considered as Bulk and otherwise as regular. A total of 5726 orders were placed off which 797 orders were bulk orders i.e. 14\%. This $14 \%$ bulk purchase was further found contributing $24 \%$ of the purchase cost i.e. $24 \%$ in the total purchase cost. We further went on and categorized our products bought from vendors stationed in about more than 7 countries. Indian vendor regions were also studied and found out that central region was the most preferred one being the most easily accessible.

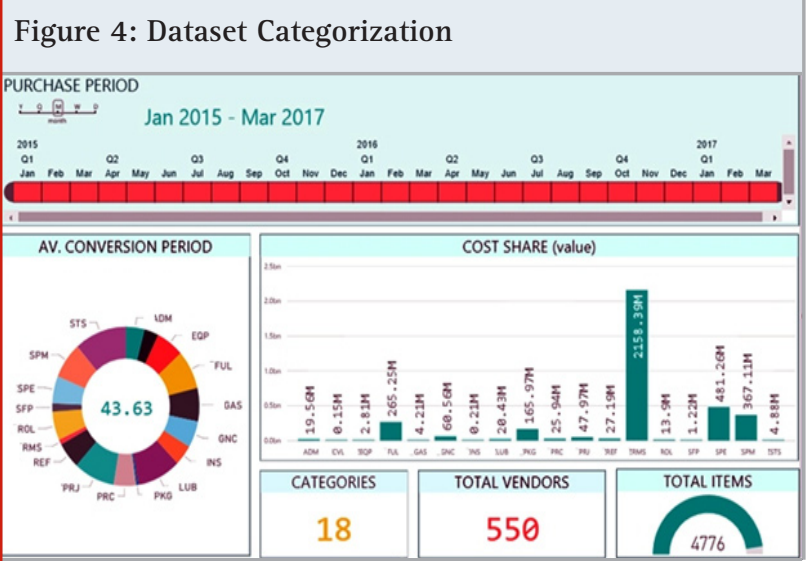

The PR to PO conversion time was calculated by counting the number of days from PR Release to PO Release and this data obtained was further categorized and analyzed of these categories, some were further studied based on the material types, i.e. \% contribution of each material type towards completion of these orders within the categorized time.On studying these trends, we found that SPM and SPE (Spare Parts Mechanical and Spare Parts Electrical) had the most conversion time.

The purchase department needs to find a new party/ vendor who can supply the product. This process takes more time, hence PR to PO cycle time for mechanical and electrical spares is more. The reason behind it was the contract for raw material and fuels and consumption were given on yearly basis. But in mechanical and electrical spares, every time an order is a new item. We also plotted the graphs for some categories. After analysis of those graphs we found the result similar to Power BI that maximum numbers of orders are of mechanical 
spares and electrical spares, and the average number of days required for these items are also high. The below figure 7shows the number of orders processed in last six months, the maximum numbers of days it took for one order completion and average number of days it took for all the orders to get completed for different categories.

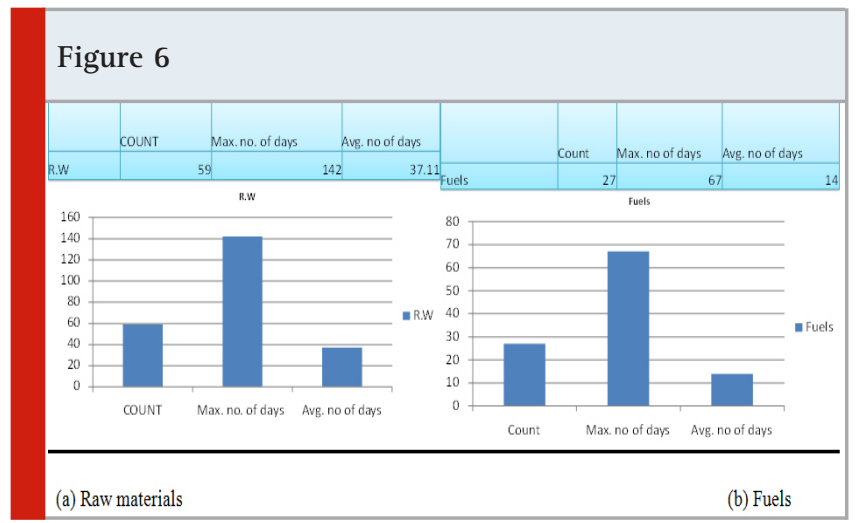

During the process execution if there is breakdown in the line and spare parts are not readily available, the whole process gets delayed. To overcome with this situation different used standard maintenance strategies are: run to failure, Preventive Maintenance.The parts used for different lines which perform the same function had different diameters. Standardization of these Bridle Rolls will lessen the inventory to be stocked and thus reduce the inventory holding cost.

Figure 7: Detailed analysis of various categories

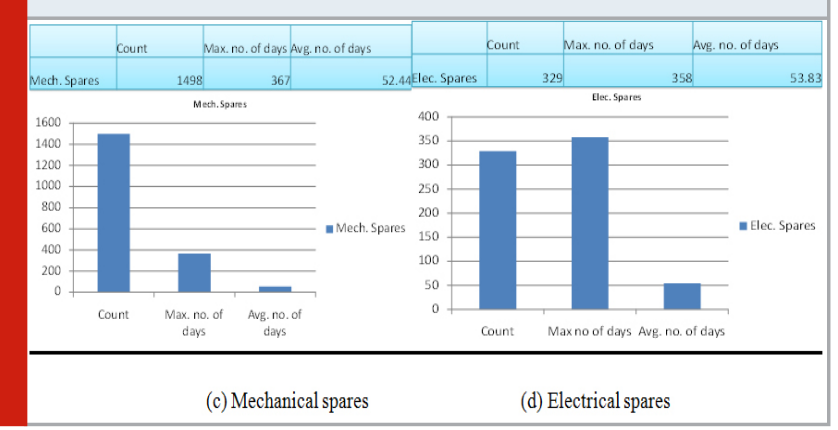

Moreover, in case a breakdown occurs in one line, parts can be replaced from some other line so that the line won't stop and shutdown cost won't be incurred. In future we will provide a solution to reduce PR to PO time that can also help in breakdown issue.

\section{CONCLUSION}

This paper deals with various aspects of the process of Purchase Requisition to Purchase Order and their analysis. We sorted and organized the data procured by us and analyzed it in various ways.

- We have analyzed the cycle time required for purchase requisitions to get converted to purchase orders, the average time of which was found to be 44.33 Days.
- The PR to PO conversion time was calculated by counting the number of days from PR release to PO release and this data was further categorized and analyzed. 2147 orders got converted from PR to PO within less than 10 days whereas 285 orders took more than 180 days to get converted from PR to P0, with the highest being 665 days.

- We have analyzed that the average number of days for PR to PO conversion is maximum in mechanical spares and electrical spares, the maximum number of orders were placed for mechanical spares.

- SPM (Spare Parts Mechanical) and SPE (Spare Parts Electrical) were recognized to be contributing to conversion time and also had major contribution in cost. If we reduce this conversion time, the company can benefit a lot.

- On studying the process, we observed that when breakdown occurs and parts aren't available, huge losses are incurred. This can be reduced by standardizing certain parts. This will also benefit the procurement process and reduce the conversion me.In future to identify the lacunas that caused this delay, we will study procurement process in more detail and will apply data mining techniques to extract the time delay cause.The solution will help to reduce PR to PO time that can also help in breakdown.

\section{REFERENCES}

Ballou, Ronald H. "The evolution and future of logistics and supply chain management." European business review 19.4 (2007): 332-348.

Bowersox, D. J., Closs, D.J., \&t Cooper, MB. (2010). Supply chain logistics management. (3rd edition). Singapore: McGraw-Hill.

Famili, A., et al. "Data preprocessing and intelligent data analysis." Intelligent data analysis 1.1 (1997): 3-23.

Hira, Swati, and P. S. Deshpande. "Data analysis using multidimensional modeling, statistical analysis and data mining on agriculture parameters." Procedia Computer Science 54 (2015): 431-439.

JSW Group, "https://www.jsw.in/".

Keim, Daniel A., et al. "Challenges in visual data analysis." Tenth International Conference on Information Visualisation (IV'06). IEEE, 2006.

Lachev, Teo, and Edward Price. Applied Microsoft Power BI: Bring your data to life!.Prologika Press, 2018.

MitraDebnath, Roma, and V. J. Sebastian. "Efficiency in the Indian iron and steel industry-an application of data envelopment analysis." Journal of Advances in Management Research 11.1 (2014): 4-19.

Raj, Raghavendra, Shun Ha Sylvia Wong, and Anthony J. Beaumont. "Business Intelligence Solution for an SME: A Case Study." KMIS. 2016.

Xue, Xiao, Zhe Wei, and Zhifeng Zeng. "Framework of Analyzing Service-Centric Cluster Supply Chain: A Case Study of Collaborative Procurement.” JSW 7.4 (2012): 733-740. 